\title{
Weather and Lockdown Compliance
}

\author{
Michael Ganslmeier ${ }^{+}$,Jonathan Van Parys $\approx$, Tim Vlandas $*$
}

Version: 12 June 2021

\begin{abstract}
The effectiveness of containment measures depends on both epidemiological and sociological mechanisms, most notably compliance with national lockdown rules. Yet, there is growing discontent with social distancing rules in many countries, which is expected to intensify further during summer. Using a highly granular dataset on compliance of over 105,000 individuals in the United Kingdom (UK), we find that compliance with lockdown policies tends to be high in the overall population, but that specific segments of society are substantially less compliant. Our findings show that warmer temperatures decrease non-compliance with governmental guidelines of individuals who are male, divorced, part-time employed, and/or parent of more than two children. Thus, as long as heard immunity through vaccination is not achieved and new strains demand containment measures to remain in place, understanding the individual determinants of non-compliance behaviour in different seasons of the year will remain important for policymakers to design effective policies in the future.
\end{abstract}

Keywords: Covid-19, pandemic, UK, lockdown, compliance, social distancing.

\footnotetext{
+ University of Oxford and University College London. Address: University of Oxford, 32 Wellington Square, OX1 2ER Oxford, United Kingdom Email: michael.ganslmeier@spi.ox.ac.uk

$\approx$ YouGov.

Address: YouGov, EC1Y 8RT London, United Kingdom

Email: jonathan.vanparys@yougov.com

$\div$ University of Oxford. Corresponding author.

Address: University of Oxford, 32 Wellington Square, OX1 2ER Oxford, United Kingdom Email: $\underline{\text { tim.vlandas@spi.ox.ac.uk }}$
} 


\section{INTRODUCTION}

In 2020, the covid-19 pandemic cost over 1.8 million lives $^{1}$ and led to more than 33 million layoffs worldwide $^{2}$. To limit the spread of the virus, governments around the world have resorted to imposing large-scale containment measures, most notably lockdowns on authorized economic activity and social interactions ${ }^{3}$. Several studies have demonstrated the crucial importance of isolating infected individuals and imposing these restrictions on individual behavior to limit the spread of the disease $\mathrm{e}^{3-5}$. Others have explored compliance (or intention to comply) with lockdown restrictions with an emphasis on effectiveness. For instance, it has been shown that compliance depends on partisanship ${ }^{6,7}$, gender $^{8}$, news media ${ }^{9}$ and civic capital ${ }^{10}$.

Despite these contributions, we still know relatively little about how weather impacts noncompliance behavior with social distancing rules among citizens. Since lockdown measures are particularly costly - both in economic and psychological terms - especially for certain individuals $^{11-13}$, one could expect that the willingness of these groups to follow governmental guidelines will decline as the opportunity costs of compliance increases sharply with higher temperature levels. Thus, even if good weather may limit the virus spread in epidemiological terms, increasing non-compliance among certain citizens during summer may limit the effectiveness of containment measures.

In the present article, we identify how demographic and socio-economic factors as well as the weather impact non-compliance with national lockdown rules. To do so, we use a large survey dataset by YouGov that records over 105,000 individual responses about (declared) compliance behavior nested in 147 sub-national administrative units in the UK between 23rd of March and 18th of May 2020. This dataset represents one of the largest individual level surveys recording 
lockdown compliance behavior over time in a single country and its highly geographically granular structure allows us to match individual responses to weather conditions at a particular time and in a specific place.

The UK is an ideal case study for investigating compliance because it has experienced a particularly deadly early pandemic period coupled with a long-standing national lockdown. A limitation of our analysis is that it focuses on a single country that has already achieved remarkable progress in its vaccination campaign. However, it is not yet clear whether vaccination will protect against all new strains (e.g. the Delta variant), and the question of individual level drivers of compliance will therefore remain key for policymaking responses to the virus. Since the coronavirus and its emerging mutations may remain an issue for the years to come, social distancing and hygiene rules, among other public health instruments, will be important tools to prevent similar public health crises in the future. In addition, due to the demographic, economic and political similarities between the UK and other advanced economies, we believe that our results are also informative for most advanced economies, which will depend on social distancing and other public health instruments.

\section{METHODS}

\section{Data}

Our empirical analysis relies on a survey dataset compiled by YouGov. It consists of 111,694 respondents in the UK surveyed between 23rd of March and 18th of May 2020. YouGov has a global online panel of 14 million people, which it has used to run extensive surveys of people in countries affected by Covid-19. Significant portions of these covid-specific surveys are now available to the academic community, including a 30-country behavior tracker in partnership with 
Imperial College London ${ }^{18}$. There is a burgeoning literature using these YouGov Covid-19 surveys, for instance elderly people's response to covid- $19^{19}$.

For the present article, we were granted access to the YouGov survey which consists of 105,512 individuals, fielded daily to a nationally representative sample over a 55-day period between March and May 2020. Such a large representative sample size is very rare in the world of social science surveys because the prohibitive costs required to run such large-scale data collection exercise in one single country. For comparison, the European Social Survey typically covers between 1000 and 3000 individuals in each country, so achieving large sample sizes then requires pooling many countries and waves.

Beyond the pure volume of the dataset, the survey provides an unprecedented temporal and geographical granularity (147 regions over 55 days) which is essential for the present research design at hand (Figure 1). On the one hand, the evolution of the pandemic has shown that the situation in a region can change very quickly and lead to large heterogeneity across regions and time periods, even within countries. To account for these confounding factors and in this way isolate individual-level determinants from geographical and time-varying once, the high regional and temporal granularity enables us to control for different sources of unobserved heterogeneity through appropriate fixed effects. On the other hand, since we are interested in the effect of weather on compliance behavior, our research design requires climatological indicators for each survey responses. Here, the detailed information about the location and time when and where the survey was taken enables us to match high-quality weather variables to each observation in the survey. This is particularly important for the UK where the weather can differ substantially across regions and change quickly even throughout the day. 
Figure 1: Variation in share of non-compliance across regions and over time.

(A) March 2020

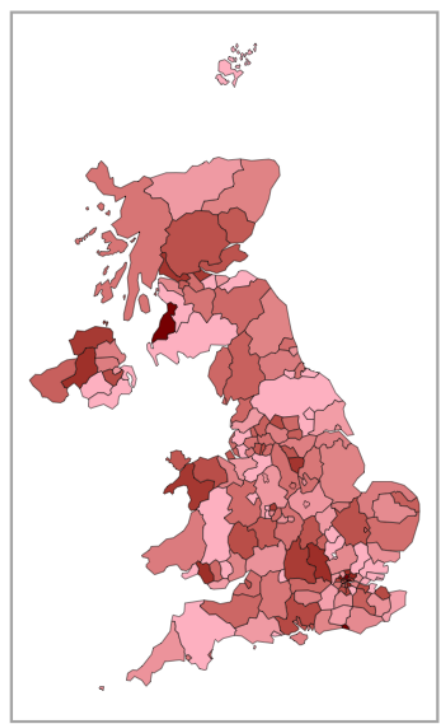

(B) April 2020

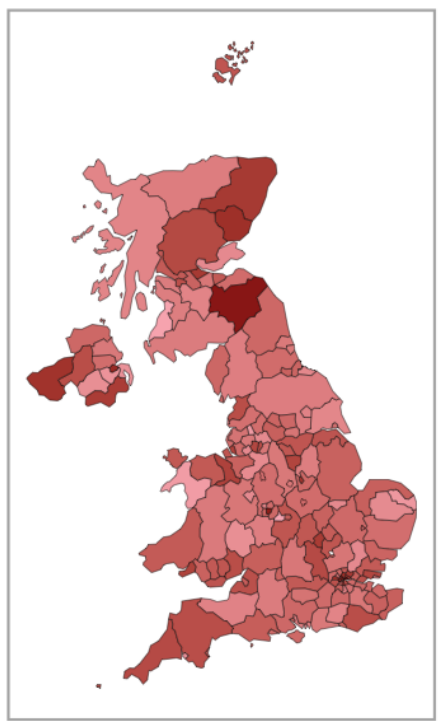

(C) May 2020

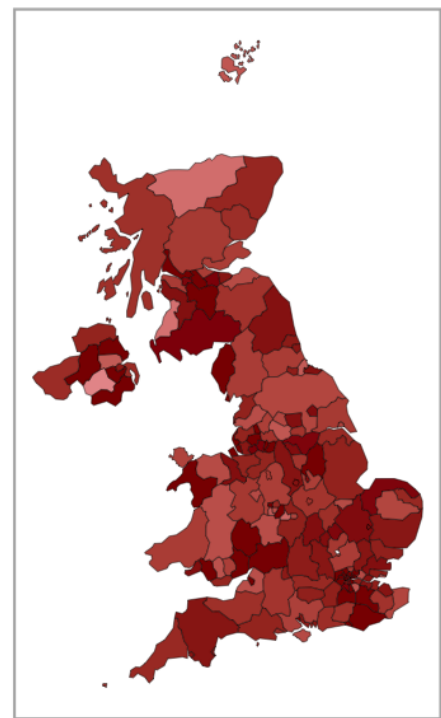

\section{$0.0 \% \quad 2.5 \% \quad 5.0 \% \quad 7.5 \% \quad 10.0 \%$}

Note: The panels show the share of non-compliers for each NUTS3 region for different months. In general, non-compliance was the highest in May $(C)$ and the lowest in March (A), although regional variation exists in all months. Sample weights are applied. $N=105,512$.

Our dependent variable of interest is based on the survey question "Which comes closer to describing you?". This question has three answer options: (A) "II will probably follow the advice of the government even if I don't agree with it or find it pointless"; (B) "I will probably do my own thing, regardless of government advice"; and (C) "Don't know". We transform this into a binary variable coded 1 if one chooses option (B), and 0 if one chooses option (A). We drop observations about individuals who choose option (C). In total, 105,512 participants have answered this question with (A) or (B). 
Figure 2 illustrates the average share of non-compliance responses for each date covered in the dataset with $95 \%$ confidence intervals (represented by the vertical lines). It also reports a smoothed function of the weighted conditional means based on previous values of the daily average response (blue line). Overall, the upwards trend is clearly visible with an accelerating rate when the plan for re-opening was announced on 10th May 2020. The upward trend of non-compliance is in line with the average temperature in the UK in the same period, as shown in Figure A1 in the appendix. Moreover, there is also a substantial spike in non-compliance responses observable when Prime Minister Johnson announced the government's plans to ease lockdown on May 10, 2020. Although it is not the primary focus of the present paper, we note that the communication strategies of containment policies appear to have a substantial impact on subsequent changes in the compliance responses.

We have cross-checked our non-compliance dummy variable with the (inverted) country-level residential mobility measure provided by Google ${ }^{14}$ (Figure 2). Although the mobility and compliance do not measure exactly the very same concept, a high correlation between the two should be present if our measure has prima facie validity. The Spearman correlation coefficient between the two measures is 0.85 . In a linear univariate regression with the aggregated compliance measure as dependent variable and the google mobility indicator as independent variable, the Rsquared reaches 0.72 . The fact that inverted residential mobility variable is able to explain large parts of the variation in non-compliance at the national level gives us confidence in the validity of our dependent variable. If anything, the potential non-disclosure and social-desirability bias of the survey means our estimates are conservative, thereby underestimating the true share of noncompliance. 
Figure 2: Share of non-compliers from end of March until mid of May.

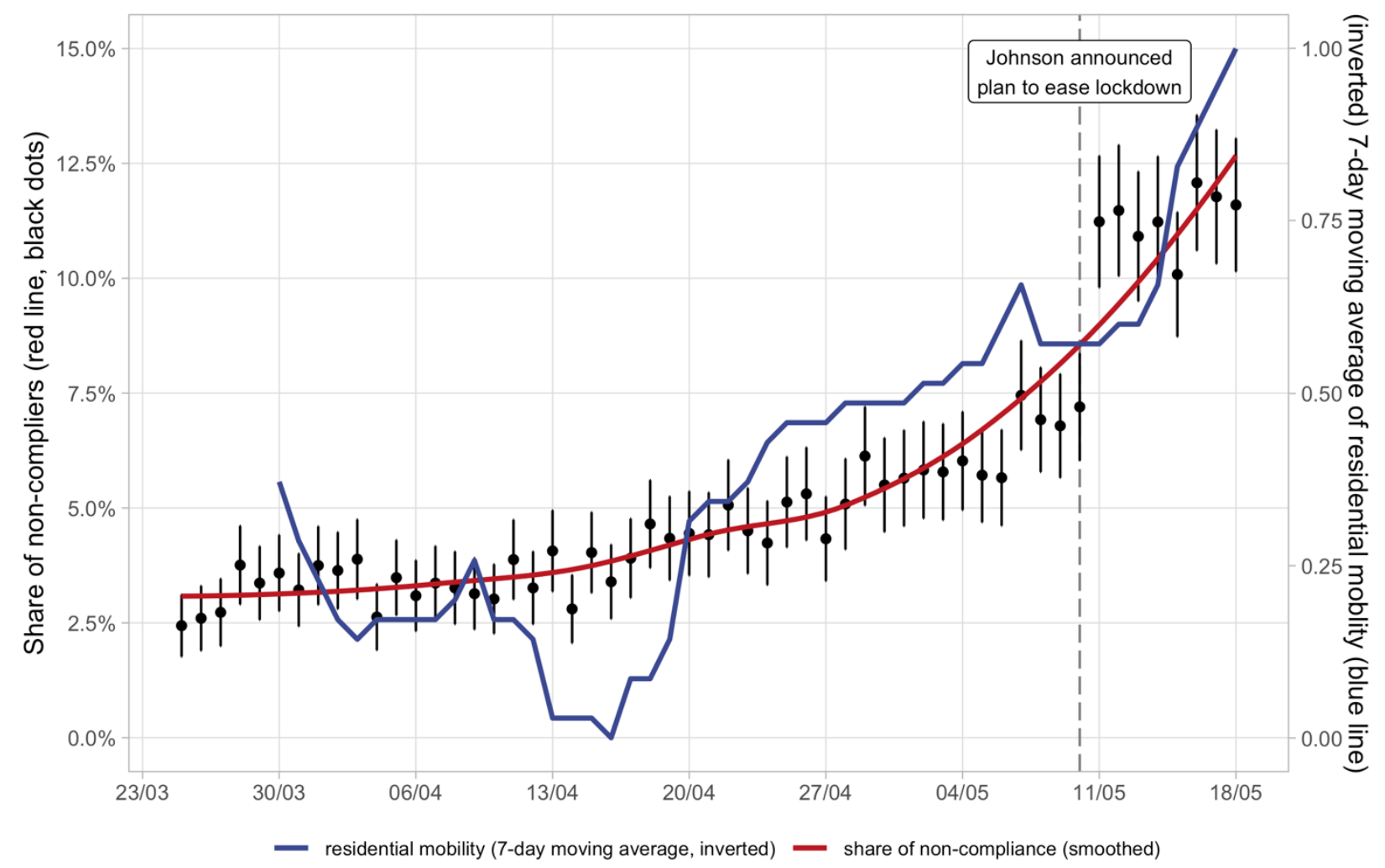

Note: On the 10th of May 2020, Prime Minister Johnson announced the government's plan of exiting lockdown, which has led to a significant jump of the share of non-compliers. The plot shows the average non-compliance shares for each day (black dots) with the corresponding $95 \%$ confidence intervals (vertical lines) (sample weights are applied). The blue line is a smoothing function based on noncompliance averages from previous days. The red line represents the (inverted and rescaled to a 0-1 range) 7-day-moving-average of the residential mobility indicator provided by Google. $N=105,512$.

However, since the mobility indicator quantifies behavior at the regional instead of the individual level, we conduct an additional cross-validation test by examining specific behavioral questions to respondents. More specifically, as Figure A2 in the appendix shows, respondents who report that (A) they leave home for a longer period, (B) they go to pursue fun activities, or (C) they do not focus extensively on self-isolation, all indicate substantially higher shares of reported noncompliance than their respective peer groups. Thus, since both cross-validation checks at the micro and macro level are in line with our compliance measure, we believe that our dependent variable is a good proxy of actual compliance. 
The survey also includes information capturing important individual characteristics of the respondents. Based on previous theoretical and empirical work in political science and sociology, we use the following individual level variables: (i) gender (male, female); (ii) age groups (18-24, 25-34, 45-54, 55-65, 65+); (iii) education level (high, medium, low); (iv) social grade (AB, C1, C2, DE); (v) marital status (married, not married, divorced, widowed); (vi) number of children (0, 1, 2, 3 or more); and (vii) employment status (full-time, part-time, unemployed, student, retired and others). The education level variables are aggregates consisting of 18 different degree types. The social grade classification is based on Social Grade system developed by the National Readership Survey. All of our independent variables are binaries to facilitate interpretation. While there are further potential indicators included in the dataset that could be beneficial for the empirical analysis (i.e., partisanship self-identification or income levels), we do not include them in the empirical model because of limited data coverage.

Finally, we have collected highly granular weather indicators (temperature, solar radiation and total precipitation) from the ERA5 dataset from the Copernicus satellite program. The Copernicus project - funded by the European Commission - uses satellites to collect data on climatology and weather indicators on a near-real-time basis since 1979. The ERA5 dataset provides weather indicators on an hourly basis with a spatial resolution of $\sim 28 \mathrm{~km}-\mathrm{by}-28 \mathrm{~km}$ near the equator $\left(0.25^{\circ}\right.$ $\mathrm{x} 0.25^{\circ}$ ). This high granularity at the geographical level is important to match valid weather indicators to the exact location of the respondent. With respect to the temporal frequency, we collapse these hourly weather variables to "day/nighttime" indicators by averaging the hourly values in four groups: (i) forenoon (06AM-11AM); (ii) afternoon (12AM-5PM); (iii) evening (6PM-11PM) and (iv) night (12PM-5AM). Thus, for instance, if a person has started the survey at 14.36PM, the respondent will be matched to the weather indicators averaged for afternoon values 
of that particular date. Although we do not report estimations using the raw hourly weather indicators, our estimates are robust towards different ways of weather operationalization and measurement.

Table A1 in the appendix provides additional information on definition, source and summary statistics for all variables used in the empirical analysis.

\section{Empirical approach}

Our empirical strategy consists of two steps. In the first, we investigate how individual level factors are generally associated with non-compliance. In the second, we analyze how the effect size of these socioeconomic determinants differs under various weather conditions. In terms of independent variables, we focus on three weather indicators, while we control for eight individual level socio-demographic and socio-economic characteristics: gender, age groups, education, social class, marital status, number of children, and employment status (see distribution among noncompliers in Figure A3 in the appendix). In our baseline specification, we use a logistic model by regressing the non-compliance measures on the individual level characteristics of the respondents in the following form:

$$
\log \left(\frac{p_{i}}{1-p_{i}}\right)=\beta_{0}+\beta_{k} \mathrm{X}_{k, i}+\alpha_{\mathrm{r}}+\gamma_{\mathrm{t}}+\varepsilon_{i}
$$

where $p_{i}$ is the probability of an individual $i$ not complying; $X$ is a matrix of $\mathrm{k}$ individual level variables; $\alpha_{\mathrm{r}}$ and $\gamma_{\mathrm{t}}$ are region and date fixed effects with region $r$ and date $t$, respectively; $\varepsilon_{i}$ is an individual-specific error term. The regional and date fixed effects are included to control for 
unobserved cross-regional and temporal heterogeneity. This enables us to control for confounding factors at the date and regional levels, which might influence non-compliance behavior. In this way, we aim to limit omitted variable bias and related endogeneity concerns.

\section{RESULTS}

\section{Non-compliance strongly depends on socio-economic characteristics}

Figure 3 plots the predicted probabilities (with 95\% confidence intervals) of the individual-level characteristics and the weather indicators with all other control variables being held constant at their mean values (see Tables A2, A3, A4, and A5 in the appendix for robustness checks). Even though a vast majority of respondents declare that they follow the government's lockdown guidelines ( $95 \%$ among all survey participants), our results point out that there exists large variation across individuals depending on demographic as well as socio-economic factors are strong predictors of non-compliance. Five individual-level characteristics deserve particular attention.

First, the largest effect is captured by gender: female respondents have a predicted probability below $3 \%$ of non-compliance compared with $6 \%$ for male respondents. In other words, the likelihood of non-compliance is more than twice as large for male than for female respondents. This finding is in line with previous results showing that compliance is significantly higher among women than $\operatorname{men}^{8}$.

Second, younger individuals between 25 and 34 (and to a lesser extent, respondents between 35 and 44) have a significantly higher predicted probability of not following governmental advice compared to people above 45 . These results are prima facie consistent with evidence of that 
mortality rates are rising with age, which may increase the incentives to follow government policies. Surprisingly, very young adults between 18 and 24 do not significantly differ from people aged above 45, although note the larger confidence interval.

Figure 3. Predicted probabilities (in \%) for non-compliance with lockdown policies.

(A) gender

(B) age group

(C) education

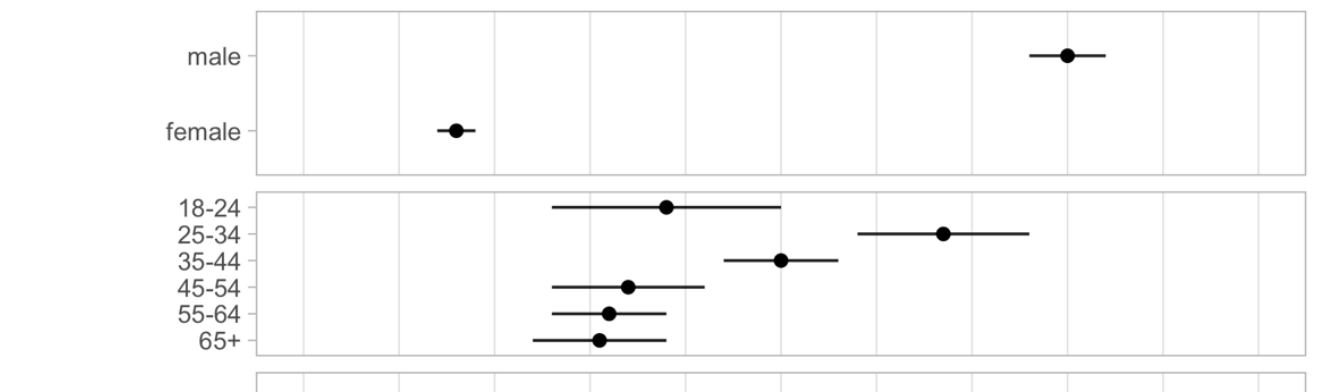

(B) age group

(D) social class

(E) marital status

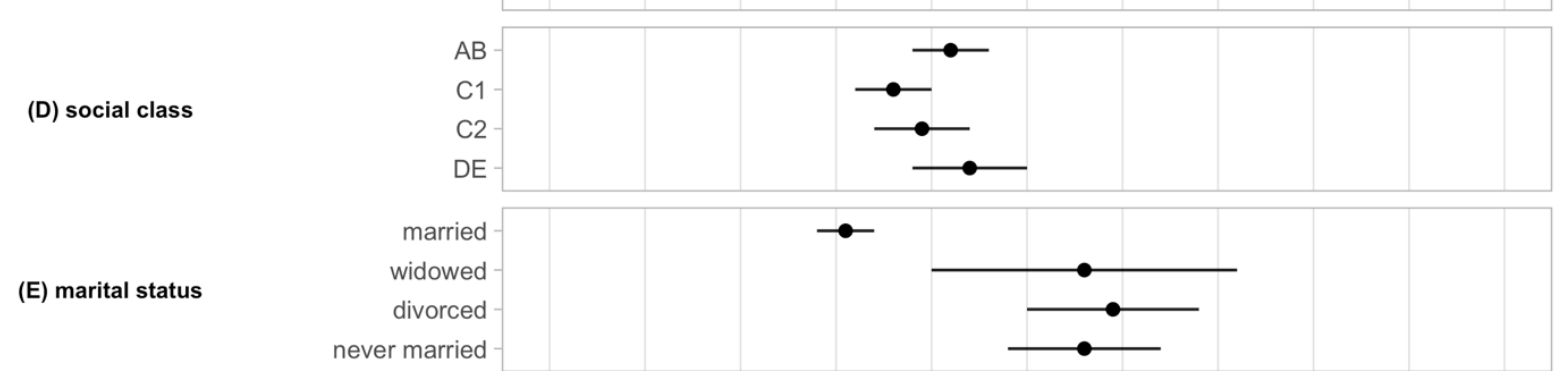

(F) no. children

(G) work status
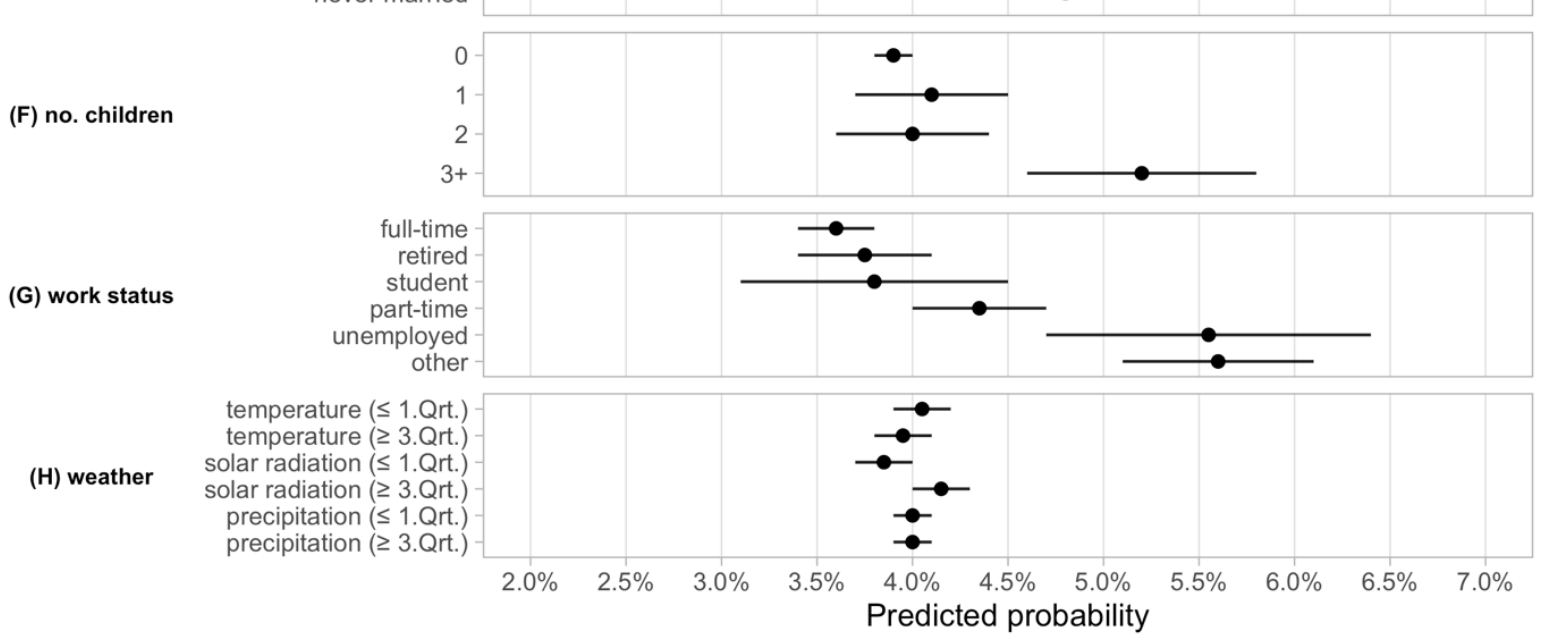

Note: The plot shows the predicted probability of non-compliance when each individual level characteristic being equal to 1 , while all other covariates are held constant at their mean values. The estimates are based on a logistic regression with date and region fixed effects included and robust standard errors clustered at the region level. The horizontal lines show the $95 \%$ confidence intervals. $N=$ 105,512 . 
Third, labor market status has a sizeable influence on non-compliance. The unemployed have a $5.6 \%$ predicted probability of non-compliance compared to $3.6 \%$ for individuals with a full-time contract. Similarly, respondents with more precarious contracts (part-time and others) tend to have higher predicted probabilities of non-compliance than workers in more standard employment. There are no statistically significant differences between students, retired people and full-time employed people.

Fourth, marital status and family size displays also important differences. Marriage increases the predicted probability of compliance whereas having more than two children lowers it. Interestingly, being 'not married at all', 'widowed', or 'divorced' exhibit similar predicted probabilities of non-compliance. These findings are in line with previous results showing that loneliness and intensifying family conflicts in larger households generate large psychological costs on certain groups of society during national lockdown ${ }^{12}$.

Fifth, the effects of social class and education are more mixed. Class appears to have no statistically significant effect, which is surprising given the potential differences in incomes across classes as well as the distinct material costs of complying between different social classes. However, lower education is significantly associated with a lower predicted probability of not following government rules. This result runs against much conventional wisdom and is not driven by multicollinearity: correlation between education and social class is not high and including only one factor at a time does not change our findings (see Table A4 in the appendix). 


\section{Warmer temperatures increase non-compliance}

Even though the seasonality of the pandemic and its dependence on climatology has been the focus of much epidemiology research ${ }^{15,16}$, weather is mostly overlooked in compliance studies, although it has a potential relevance of weather effects for social behavior. Exploiting highly granular satellite data ${ }^{17}$, we are able to match each respondent to the exact time of interview and location. This is important because weather conditions can vary substantially across regions and over time (see Figure A1 in the appendix).

Overall, as the bottom panel of Figure 3 illustrates, non-compliance is not generally associated with weather after controlling for individual-level, regional and time-varying factors. However, analyzing how compliance of individuals with specific characteristics are affected by weather conditions reveals that this null overall effect hides substantial amount of individual heterogeneity. When splitting the sample along key weather indicators, we find that certain socioeconomic groups show a strong reaction to changing weather conditions (Figure 4 - see also Figures A5 and A6 in the appendix), while others remain largely unaffected. The heterogeneous effects of weather are substantial for temperature, moderate for solar radiation, and largely minor and/or statistically insignificant for precipitation.

Moreover, the largest amplification of the predicted probabilities under warm temperature conditions can be observed for four individual level characteristics: being male, being divorced, being part-time employed, and having more than two children. For instance, while the probability of non-compliance for female respondents rises from $2.1 \%$ under cold temperature to $3.2 \%$ under warm temperature, for male respondents the probability increases from $4.5 \%$ to $6.5 \%$ between cold and warm periods. Divorced individuals as well as parents of more than 2 children show an even 
greater sensitivity to temperature changes with non-compliance probabilities in warmer environments being more than twice as large compared to colder periods.

Figure 4. Predicted probability for different characteristics and temperature levels.

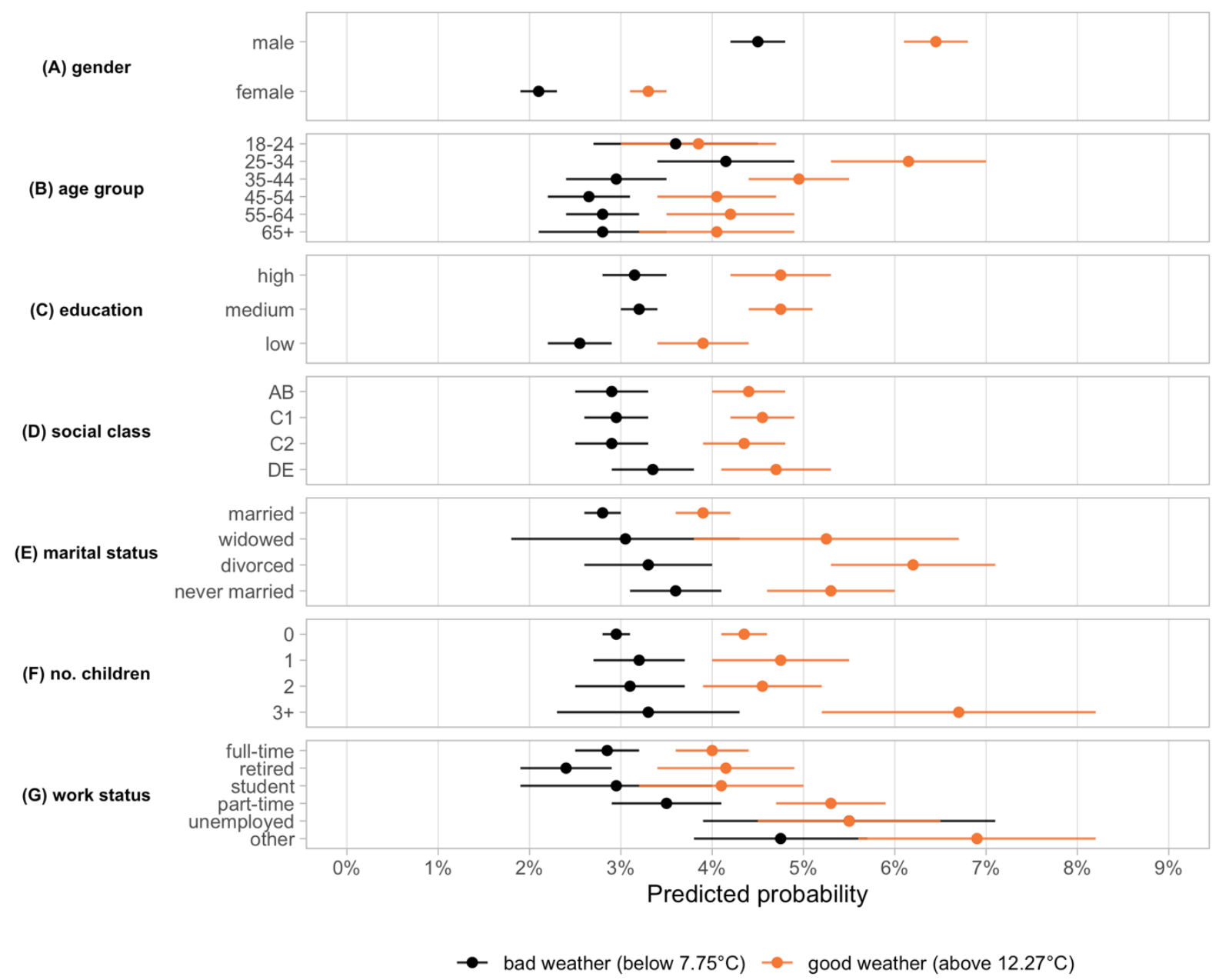

Note: The panels show the predicted probability of non-compliance when a given individual level characteristic being equal to 1 while all other covariates are held constant at their mean values. The black (orange) dots are estimates based on observations under bad (good) weather conditions, which are defined along the top and bottom quartiles $\left(7.75^{\circ} \mathrm{C}\right.$ and $12.27^{\circ} \mathrm{C}$, respectively) of temperature. The estimates are based on a logistic regression with date and region fixed effects included and robust standard errors clustered at the region level. The horizontal lines show the $95 \%$ confidence intervals. $N=105,512$. 
Overall, our results are in line with an 'opportunity cost' logic: when temperature levels are high, compliance becomes a more costly choice - especially for the young, single individuals and large families - as the missed (social) opportunities are greater on warm days compared to cold periods of the year. Thus, while a broad range of epidemiological studies document a seasonality in the spread of the virus with lower incidence in times of good weather ${ }^{15,16}$, our findings reveal the potential presence of an opposite social mechanism operating through changes in human and social behavior. This greater non-compliance might in turn facilitate the transmission of the virus on warm and sunny days.

\section{Robustness checks}

Moreover, we test whether our findings are robust to different fixed effect structures. The results do not dependent on the in- or exclusion of temporal or regional fixed effects (Table A2 in the appendix, column 1-4). Another concern might be that confounding factors within regions at a certain period are driving non-compliance behavior, such as external shock (i.e. abrupt virus spread) that only matters to a certain region at a specific time. Including regional and date fixed effects individually would not absorb this variation as they estimate average effects for a given region (over the whole period) or a particular date (across all regions). Thus, we address this issue by including NUTS1-Date fixed effects (interaction between date and NUTS1 binaries) and NUTS2-week fixed effects (interaction between week and NUTS2 binaries). Again, our estimates are very similar to the baseline results (Table A2 in the appendix, column 5-6).

One might also be interested whether the variation in non-compliance originates from local pandemic situation. In other words, the question is whether the individual-level characteristics provide value to our estimations. Since general R-Squared might not be a suitable candidate for 
measuring goodness of fit, we resort to the Akaike Information Criteria (AIC). As Table A2 in the appendix shows, all estimations reach AIC values of $\sim 39,000$. When we drop all individual-level independent variables and only include NUTS1-Date fixed effects (interaction between date and NUTS1 binaries) (as in column 5), the AIC increases to over 42,000. In other words, using the individual-level covariates provides value for the goodness of fit and the explanatory power of our control variables seem to matter after local time-varying factors (such as number of new cases) have been accounted for.

In addition, since the baseline uses standard errors clustered at the regional level, we also run robustness checks by using different standard error types, namely (i) uncorrected, (ii) robust, (iii) robust clustered at region level, (iv) robust clustered at region-week level, and (v) robust clustered at region-date level. Our results show that the size of standard errors of the coefficients for different independent variables do not substantially vary depending on the type of standard error that we report (see Table A3 in the appendix).

Furthermore, another concern is related to "double measurement" of the same factor on the righthand-side. As is common for micro-level survey analysis, demographic and socio-economic variables are usually correlated (i.e., social class, employment status and/or education level), which would bias our estimates and foster model uncertainty. Although none of our independent variables are highly correlated with each other and none of the independent variables has a variance inflated factor (VIF) larger than 5 in the baseline estimation, we show that our results are not subject to multicollinearity issues by including the independent variables in a stepwise fashion (see Table A4 in the appendix). Similarly, including a time-trend does not change our findings. In addition, it is also noteworthy that we do not use income as an independent variable in any estimations 
although is seems to be quite important given the large variation observable in Figure A3 in the appendix. This is because the number of observations for income was too low which would create sampling and endogeneity issues, which are hard to address within the models themselves.

We also vary the empirical model by re-estimating our analyses using a linear probability model with region and date fixed effect:

$$
\mathrm{y}_{i}=\beta_{0}+\beta_{k} \mathrm{X}_{k, i}+\alpha_{\mathrm{r}}+\gamma_{\mathrm{t}}+\varepsilon_{i}
$$

where $\mathrm{y}_{i}$ is the non-compliance binary of individual $i ; X$ is a matrix of $\mathrm{k}$ individual level variables; $\alpha_{\mathrm{r}}$ and $\gamma_{\mathrm{t}}$ are region and date fixed effects, respectively; $\varepsilon_{i}$ is an individual-specific error term.

Next, in lieu of a fixed effect model, we choose to specify a multilevel random intercept logistic regression:

$$
\log \left(\frac{p_{i}}{1-p_{i}}\right)=\beta_{0}+\beta_{k} \mathrm{X}_{k, i}+\gamma_{\mathrm{t}}+\mathrm{u}_{\mathrm{r}}+\varepsilon_{i}
$$

where $p_{i}$ is the probability of an individual $\mathrm{i}$ not complying; $X$ is a matrix of $\mathrm{k}$ individual level variables; $\gamma_{\mathrm{t}}$ are date fixed effects; $\mathrm{u}_{\mathrm{r}}$ is the region-specific random intercept; $\varepsilon_{i}$ is an individualspecific error term. This multilevel mixed-effect specification enables us to predict the probability of non-compliance of individual i through individual-level characteristics that are nested in different regions.

In the presence of hierarchical structures, standard logistic or linear estimations tend to underestimate the standard errors and thus overestimate the corresponding p-values of predictors. 
Since there are good reasons to believe that the unit of analysis - in our case survey responses are not completely independent but rather clustered at the geographical level (i.e., due to neighborhood effects), testing the robustness of our results with a multilevel mixed effect estimation strikes us as central. Finally, we also estimate a multi-level mixed-effect generalized linear model with date fixed effects and regional random effects included. As Table A5 in the appendix show, the results are very similar in terms of effects size, significance level and the general conclusion we draw from our baseline model.

Finally, to test the mediating effects of weather conditions on the non-compliance behavior of certain groups, we adopt a sub-sampling strategy by estimating the baseline model over subsamples defined along thresholds in the distribution of our weather variables. To be more specific, we split the sample of the top and bottom $25 \%$ of (i) temperature (Figure 4), (ii) net solar radiation (Figure A5 in the appendix) and (iii) total precipitation (Figure A6 in the appendix) distribution. This gives us six sub-samples to which we apply our baseline model.

\section{CONCLUSION}

To conclude, in the absence of effective containment measures, the consequences of the coronavirus for health and the economy will be dire for countries around the world. Since most countries will not have achieved herd immunity through vaccination by the end of summer 2021, containment policies will remain essential in the fight against the virus. To guarantee their effectiveness, compliance with lockdown rules is essential, especially when full enforcement is neither feasible nor desirable. The empirical evidence provided in this paper aims to contribute to two important aspects to the pandemic literature. 
On the one hand, although a large majority reports that they follow the government guidelines ( 95\%), the share of non-compliers increased steadily in the early period of the pandemic. Importantly, non-complying citizens share common demographic and socio-economic characteristics at the individual level. Our results show that being male, aged between mid20s/early-30s, unemployed, non-married, and/or a parent with many children are dominant characteristics within the less-complying groups of society. On the other hand, our results also show that rising temperature levels does not increase non-compliance of the entire population. In contrast, during warmer periods, people with these individual characteristics show an even smaller willingness to follow lockdown rules.

For as long as new strains develop and herd immunity through vaccination is not achieved, the effectiveness of social distancing measures will remain an important tool to successfully contain this global pandemic. But even in countries with high levels of vaccination, targeted lockdowns may be crucial if new strains prove to be resistant to current vaccines. Although warmer periods are about to bring natural containment effects which may ease the fight against the pandemic, the associated increases in social gatherings and non-compliance with public health rules, particularly present among certain socioeconomic groups as identified in this article, may complicate the containment efforts. Thus, policymakers around the world are well advised to take the higher likelihood of non-compliance of certain socioeconomic groups on warm and sunny seasons into account when choosing between competing exit strategies. With the empirical evidence provided in this paper, we hope to contribute to this debate. 


\section{REFERENCES}

1. WHO (World Health Organization), COVID-19 weekly epidemiological update - 5 January 2021. (2021).

2. ILO (International Labour Organisation), ILO Monitor: COVID-19 and the world of work. Seventh edition - Updated estimates and analysis. (2021).

3. Flaxman, S. et al., Estimating the effects of non-pharmaceutical interventions on COVID-19 in Europe. Nature. 584 (7820), 257-261 (2020).

4. Maier, B. F., Brockmann, D., Effective containment explains subexponential growth in recent confirmed COVID-19 cases in China. Science. 368 (6492), $742-746$ (2020).

5. Dehning, J. et al., Inferring change points in the spread of COVID-19 reveals the effectiveness of interventions. Science. 369 (6500), (2020).

6. Painter, M., Qiu, T., Political beliefs affect compliance with Covid-19 social distancing orders. Covid Economics. 103, (2020)

7. Gollwitzer, A., et al., Partisan differences in physical distancing are linked to health outcomes during the COVID-19 pandemic. Nat Hum Behav. 4 (11), 1186-1197 (2020).

8. Galasso, V., et al., Gender differences in COVID-19 attitudes and behavior: Panel evidence from eight countries. Proc Natl Acad Sci. 117 (44), 27285-27291 (2020).

9. Simonov, A., Sacher, S., Dubé, J., Biswas, S., The persuasive effect of fox news: noncompliance with social distancing during the covid-19 pandemic. National Bureau of Economic Research. w27237 (2020).

10. Grossman, G., Kim, S., Rexer, J. M., \& Thirumurthy, H., Political partisanship influences behavioral responses to governors' recommendations for COVID-19 prevention in the United States. Proc Natl Acad Sci. 117 (39), 24144-24153 (2020).

11. Nivette, A., et al., Non-compliance with COVID-19-related public health measures among young adults in Switzerland: Insights from a longitudinal cohort study. Soc Sci Med. 268 (113370), (2020)

12. Townsend, E., COVID-19 policies in the UK and consequences for mental health. Lancet Psychiatry. 7 (12), 1014-1015 (2020).

13. Goolsbee, A., \& Syverson, C., Fear, lockdown, and diversion: Comparing drivers of pandemic economic decline. J Public Econ. 193 (104311), (2020).

14. Google LLC, Google COVID-19 Community Mobility Reports. Retrieved from: 'https://www.google.com/covid19/mobility/' [Online Resource, accessed 15 April 2021], (2021)

15. Franch-Pardo, I., Napoletano, B. M., Rosete-Verges, F., Billa, L., Spatial analysis and GIS in the study of COVID-19. A review. Sci Total Environ. 739 (140033), (2020).

16. Paraskevis, D., et al., A review of the impact of weather and climate variables to COVID-19: In the absence of public health measures high temperatures cannot probably mitigate outbreaks. Sci Total Environ. 768 (144578), (2020)

17. Muñoz Sabater, J., ERA5-Land hourly data from 1981 to present. Copernicus Climate Change Service (C3S) Climate Data Store (CDS). Retrieved from: https://cds.climate.copernicus.eu/cdsapp\#!/dataset/reanalysis-era5-land?tab=overview' [Online Resource, accessed 20 March 2021], (2019)

18. Jones, S., Imperial College London Big Data Analytical Unit and YouGov Plc. Imperial College London YouGov Covid Data Hub [Online Resource]. (2020)

19. Daoust, J., Elderly people and responses to COVID-19 in 27 Countries. PLoS One. 15(7), (2020). 


\title{
Appendix
}

\section{Weather and lockdown compliance}

\author{
Michael Ganslmeier ${ }^{+}$, Jonathan Van Parys $\approx$, Tim Vlandas $\div$
}

Version: 11 June 2021

${ }^{+}$University of Oxford and University College London.

Address: University of Oxford, 32 Wellington Square, OX1 2ER Oxford, United Kingdom

Email: michael.ganslmeier@spi.ox.ac.uk

$\approx$ YouGov.

Address: YouGov, EC1Y 8RT London, United Kingdom

Email: jonathan.vanparys@yougov.com

$\div$ University of Oxford. Corresponding author.

Address: University of Oxford, 32 Wellington Square, OX1 2ER Oxford, United Kingdom

Email: tim.vlandas@spi.ox.ac.uk

Acknowledgements. We thank Alexis Vlandas, Margaryta Klymak and Sarah Jones for their comments and suggestions. 
TABLE A1. DEFINITION, SOURCE AND SUMMARY STATISTICS OF VARIABLES

\begin{tabular}{|c|c|c|c|c|c|}
\hline Variable & Definition & Source & $\mathbf{N}$ & Mean & SD \\
\hline noncompliance & Not complying & YouGov & 105,512 & 0.0518 & 0.222 \\
\hline male & male & YouGov & 105,512 & 0.466 & 0.499 \\
\hline age1824 & age: 18 and 24 & YouGov & 105,512 & 0.0936 & 0.291 \\
\hline age2534 & age: 25 and 34 & YouGov & 105,512 & 0.156 & 0.363 \\
\hline age 3544 & age: 35 and 44 & YouGov & 105,512 & 0.166 & 0.372 \\
\hline age 4554 & age: 45 and 54 & YouGov & 105,512 & 0.161 & 0.367 \\
\hline age5564 & age: 55 and 65 & YouGov & 105,512 & 0.165 & 0.371 \\
\hline age65 & age 65 or over & YouGov & 105,512 & 0.258 & 0.438 \\
\hline socgrade $\mathrm{AB}$ & $\begin{array}{l}\text { Upper middle and } \\
\text { middle class }\end{array}$ & YouGov & 104,597 & 0.303 & 0.460 \\
\hline socgradeC1 & Lower middle class & YouGov & 104,597 & 0.295 & 0.456 \\
\hline socgradeC2 & Skilled working class & YouGov & 104,597 & 0.185 & 0.388 \\
\hline socgradeDE & $\begin{array}{l}\text { Working and non- } \\
\text { working class }\end{array}$ & YouGov & 104,597 & 0.218 & 0.413 \\
\hline eduHigh & high education & YouGov & 105,512 & 0.305 & 0.460 \\
\hline eduMed & medium education & YouGov & 105,512 & 0.432 & 0.495 \\
\hline eduLow & low education level & YouGov & 105,512 & 0.264 & 0.441 \\
\hline maritalMarried & married & YouGov & 104,831 & 0.610 & 0.488 \\
\hline maritalNotMarried & not married & YouGov & 104,831 & 0.262 & 0.439 \\
\hline maritalDivorced & divorced & YouGov & 104,831 & 0.0881 & 0.283 \\
\hline maritalWidowed & widowed & YouGov & 104,831 & 0.0400 & 0.196 \\
\hline child0 & no children & YouGov & 101,454 & 0.744 & 0.437 \\
\hline child1 & 1 child & YouGov & 101,454 & 0.119 & 0.324 \\
\hline child2 & 2 children & YouGov & 101,454 & 0.1000 & 0.300 \\
\hline child3p & 3 children or more & YouGov & 101,454 & 0.0376 & 0.190 \\
\hline workFullTime & full-time employment & YouGov & 105,512 & 0.396 & 0.489 \\
\hline workPartTime & part-time employment & YouGov & 105,512 & 0.142 & 0.350 \\
\hline workStudent & student & YouGov & 105,512 & 0.0493 & 0.217 \\
\hline workRetired & retired & YouGov & 105,512 & 0.272 & 0.445 \\
\hline workUnemp & unemployed & YouGov & 105,512 & 0.0377 & 0.191 \\
\hline workOther & other work employment & YouGov & 105,512 & 0.102 & 0.303 \\
\hline precipitation & precipitation & Copernicus & 105,506 & 0.00035 & 0.0012 \\
\hline solar_radiation & solar radiation & Copernicus & 105,506 & 5.555 & 4.886 \\
\hline temperature & temperature & Copernicus & 105,506 & 283.3 & 3.444 \\
\hline
\end{tabular}


Figure A1. AVERAgE WEATHER INDICATORS OVER TIME.

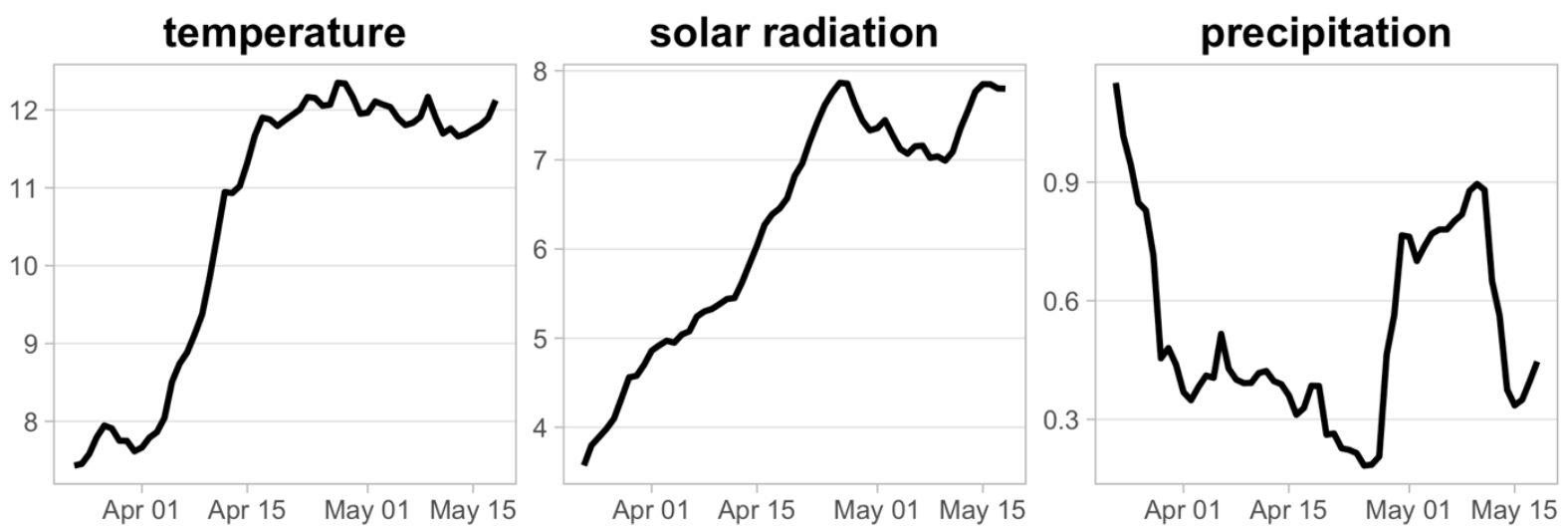

Note: The panels show average weather indicators at 12:00AM in the UK between $23^{\text {rd }}$ of March and $18^{\text {th }}$ of May 2020. The units of temperature, solar radiation and precipitation are degrees Celsius, $\mathrm{MJ}^{\mathrm{m}} \mathrm{m}^{2}$ (in Mio.) and $m \times 10^{-7}$, respectively. The figure illustrates that temperature levels are strongly increasing in the first weeks of April, similar to solar radiation. Precipitation is more volatile over time. 
FIGURE A2. ROBUSTNESS CHECKS OF NON-COMPLIANCE BY BEHAVIOURAL SURVEY ITEMS.

(A)

Yesterday, did you leave your home for any reason at all?

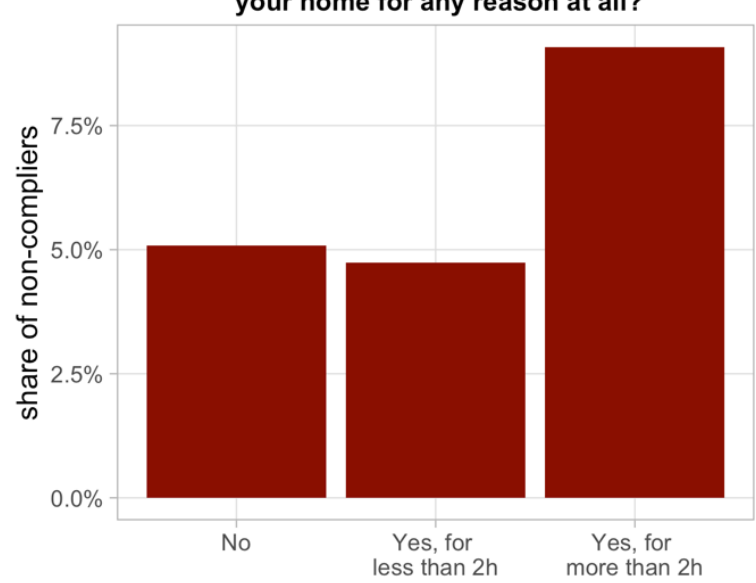

(B)

Did you go out for necessary or fun activities?

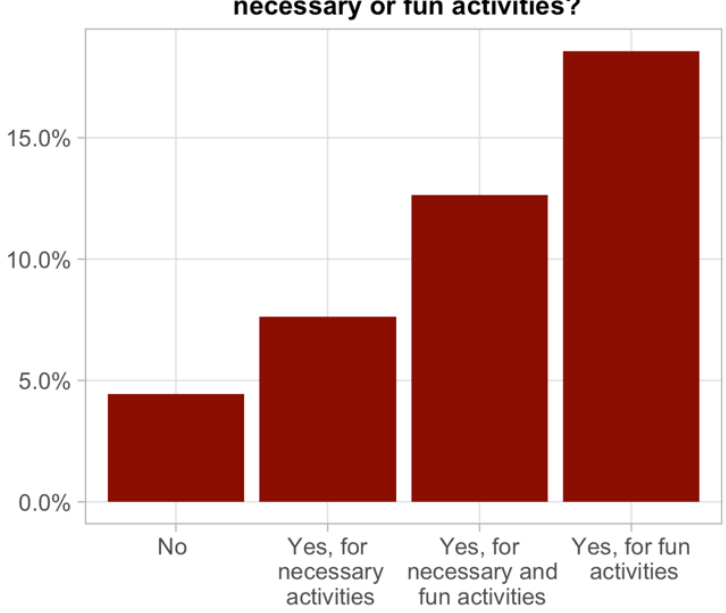

(C)

ave you self-isolated?

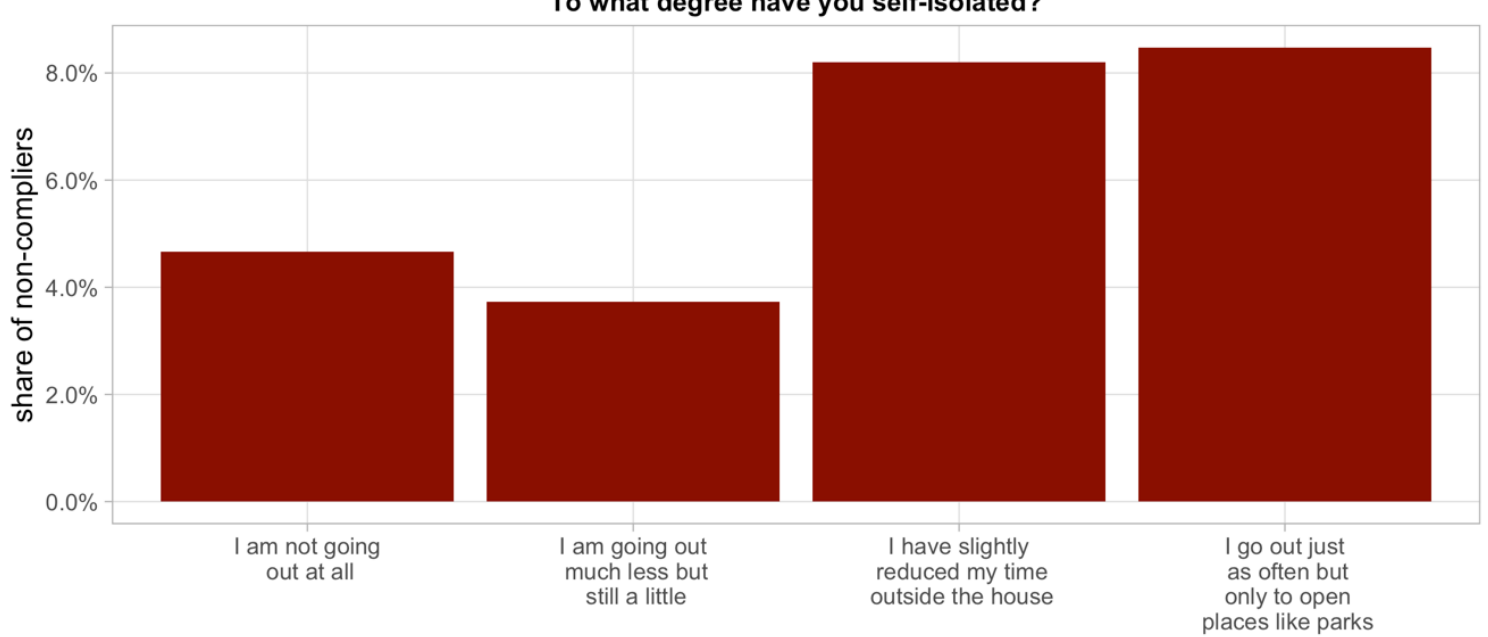

Note: The panels show the share of non-compliers for each answer to question related to actual behaviour. The figure illustrates that people who are self-isolating to a lower degree or engage in more fun activities, they are also more likely to report that they are non-compliers. Sample weights are applied. 
FIGURE A3. THE SHARE OF NON-COMPLIERS ACROSS INDIVIDUAL CHARACTERISTICS.

(A)

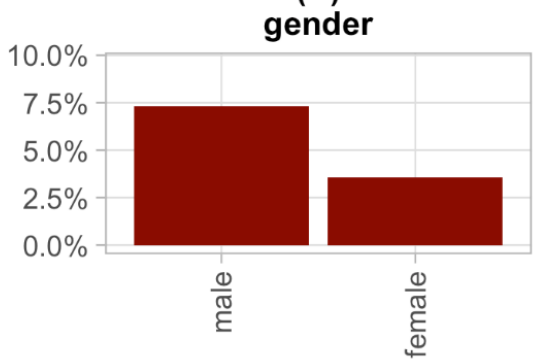

(D)

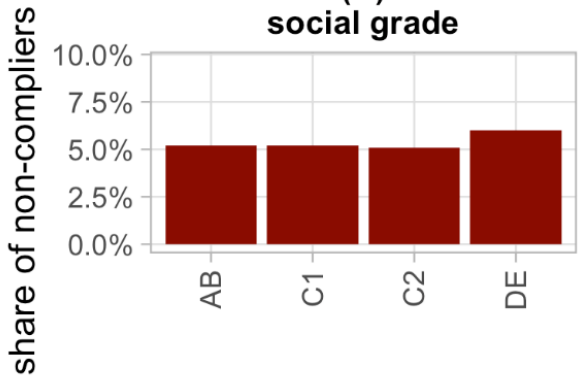

(G)

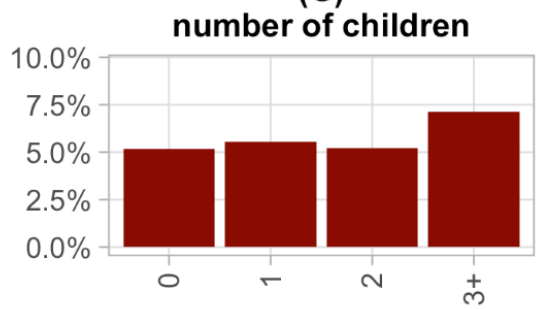

(B)

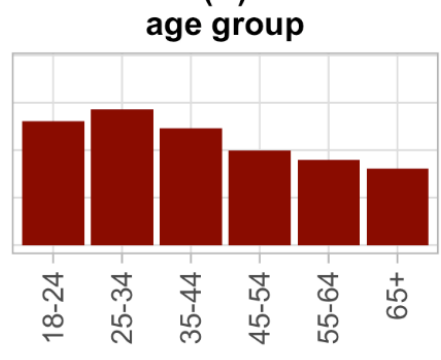

(E)

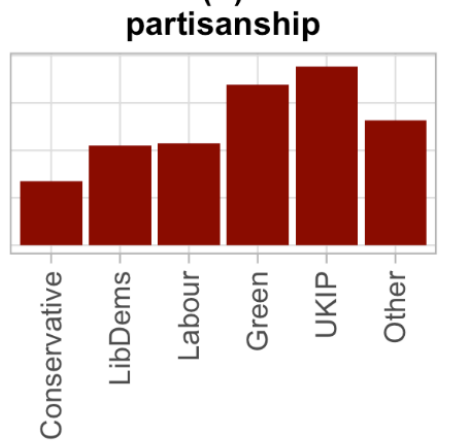

(H) employment status

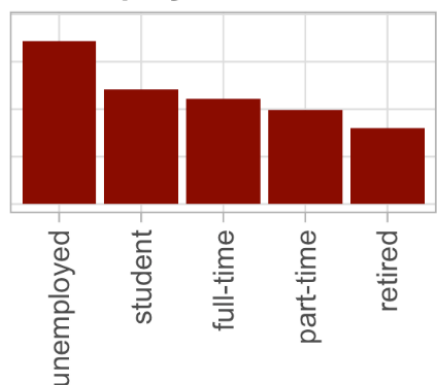

(C) education

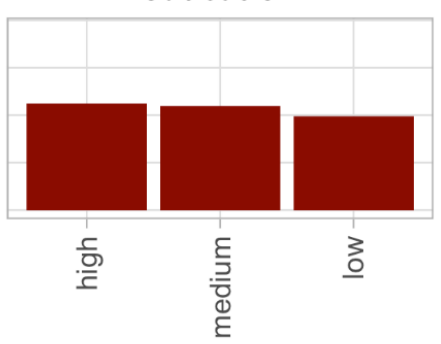

(F) marital status

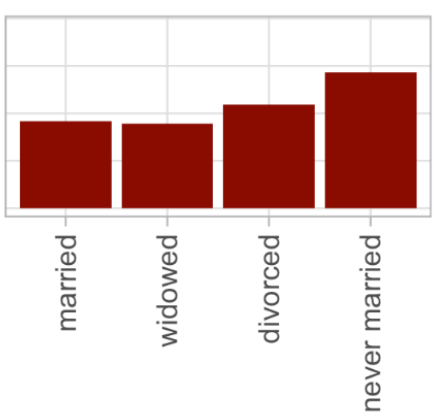

(I) annual income (in £)

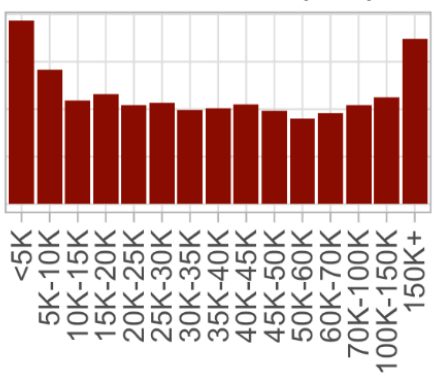

Note: The panels show the share of non-compliers for each category of selected individual characteristics. The descriptive evidence illustrates that non-compliance is the largest among people who are (i) male, (ii) young, (iii) in very low social class, (iv) green and UKIP voters, (v) never married, (vi) with many children, (vii) unemployed and (viii) with very low or very high income. Sample weights are applied. $N=105,512$ 
FIGURE A4. NON-COMPLIERS BY INDIVIDUAL CHARACTERISTICS ACROSS REGIONS.

(A)

parent of $>2$ children

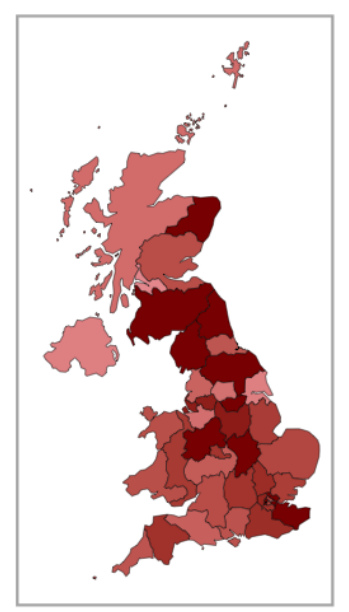

(B)

never married

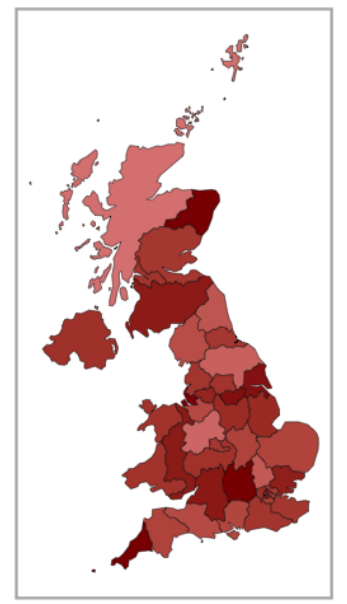

(C) lowest social class

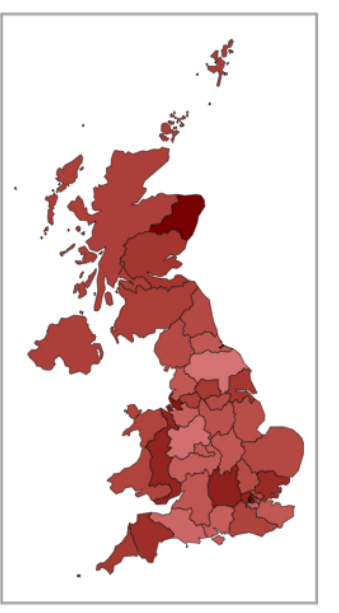

(D)

\section{unemployed}

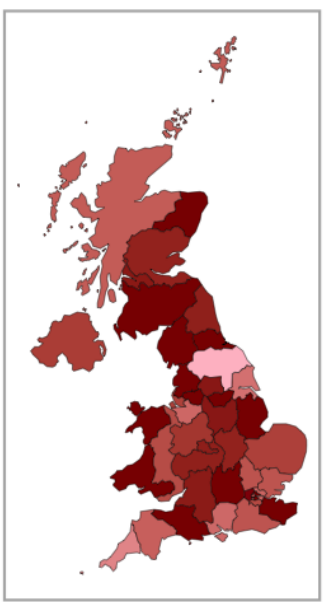

\section{$\begin{array}{lllll}0.0 \% & 2.5 \% & 5.0 \% & 7.5 \% & 10.0 \%\end{array}$}

Note: The panels show the share of non-compliers for each NUTS2 region by selected individual characteristics in the whole sample. Parents with more than 2 children and unemployed people show particular high rates of non-compliance in Northern England and Southern Scotland. Sample weights are applied. $N=105,512$ 
TABLE A2. LOGISTIC REGRESSIONS WITH DIFFERENT FIXED EFFECT STRUCTURES

\begin{tabular}{|c|c|c|c|c|c|c|}
\hline Model & (1) & (2) & (3) & (4) & (5) & (6) \\
\hline male & $0.793 * * *$ & $0.797 * * *$ & $0.798 * * *$ & $0.802 * * *$ & $0.803 * * *$ & $0.800 * * *$ \\
\hline age: $18-24$ & 0.125 & 0.101 & 0.136 & 0.115 & 0.097 & 0.116 \\
\hline age: $25-34$ & $0.418 * * *$ & $0.424 * * *$ & $0.428 * * *$ & $0.434 * * *$ & $0.426 * * *$ & $0.424 * * *$ \\
\hline age: $35-44$ & $0.252 * * *$ & $0.256^{* * * *}$ & $0.264 * * *$ & $0.270 * * *$ & $0.258 * * *$ & $0.264 * * *$ \\
\hline age: $45-54$ & 0.046 & 0.043 & 0.059 & 0.057 & 0.040 & 0.055 \\
\hline age: $55-64$ & -0.024 & -0.009 & -0.014 & 0.003 & -0.004 & 0.001 \\
\hline social grade $\mathrm{C} 1$ & -0.055 & -0.059 & -0.053 & -0.058 & -0.053 & -0.060 \\
\hline social grade $\mathrm{C} 2$ & -0.022 & -0.033 & -0.006 & -0.019 & -0.017 & -0.017 \\
\hline social grade DE & 0.038 & 0.041 & 0.045 & 0.050 & 0.059 & 0.045 \\
\hline low education & $-0.158 * * *$ & $-0.166^{* * *}$ & $-0.152 * * *$ & $-0.160 * * *$ & $-0.165 * * *$ & $-0.153 * * *$ \\
\hline medium education & -0.022 & -0.025 & -0.010 & -0.012 & -0.023 & -0.008 \\
\hline never married & $0.325^{* * *}$ & $0.338 * * *$ & $0.299 * * *$ & $0.312 * * *$ & $0.324 * * *$ & $0.307 * * *$ \\
\hline divorced & $0.344 * * *$ & $0.353 * * *$ & $0.341 * * *$ & $0.347 * * *$ & $0.343 * * *$ & $0.341 * * *$ \\
\hline widowed & $0.307 * * *$ & $0.301 * * *$ & $0.313 * * *$ & $0.306 * * *$ & $0.296 * * *$ & $0.310 * * *$ \\
\hline 1 child & 0.031 & 0.030 & 0.039 & 0.038 & 0.036 & 0.049 \\
\hline 2 children & -0.007 & -0.007 & 0.007 & 0.009 & 0.008 & 0.014 \\
\hline$>2$ children & $0.291 * * *$ & $0.285 * * *$ & $0.298 * * *$ & $0.295 * * *$ & $0.285 * * *$ & $0.288 * * *$ \\
\hline part-time work & $0.197 * * *$ & $0.193 * * *$ & $0.202 * * *$ & $0.199 * * *$ & $0.191 * * *$ & $0.201 * * *$ \\
\hline student & 0.076 & 0.061 & 0.076 & 0.058 & 0.071 & 0.059 \\
\hline retired & 0.025 & 0.020 & 0.050 & 0.047 & 0.019 & 0.044 \\
\hline unemployed & $0.514 * * *$ & $0.452 * * *$ & $0.521 * * *$ & $0.459 * * *$ & $0.445^{* * *}$ & $0.466 * * *$ \\
\hline other work status & $0.467 * * *$ & $0.452 * * *$ & $0.473 * * *$ & $0.457 * * *$ & $0.449 * * *$ & $0.463 * * *$ \\
\hline constant & $-3.700 * * *$ & $-4.541 * * *$ & $-3.733 * * *$ & $-4.594 * * *$ & $-3.062 * * *$ & $-2.975 * * *$ \\
\hline Observations & 100,357 & 100,357 & 100,357 & 100,357 & 98,687 & 99,917 \\
\hline Region FE & No & No & Yes & Yes & No & Yes \\
\hline Date FE & No & Yes & No & Yes & No & No \\
\hline NUTS1-Date FE & No & No & No & No & Yes & No \\
\hline NUTS2-Week FE & No & No & No & No & No & Yes \\
\hline AIC & 39,263 & 38,021 & 38,998 & 38,998 & 38,998 & 38,998 \\
\hline
\end{tabular}

Note: The outcome variable is the non-compliance binary. The columns differ with respect to the fixed effects (FE) included. Estimates are based on a logistic regression robust standard errors clustered at the regional level. ***,**** denote significance at 1,5 and 10 percent, respectively. 
TABLE A3. LOGISTIC REGRESSIONS WITH DIFFERENT STANDARD ERROR TYPES

\begin{tabular}{|c|c|c|c|c|c|}
\hline Model & (1) & (2) & (3) & (4) & (5) \\
\hline male & $0.802 * * *$ & $0.802 * * *$ & $0.802 * * *$ & $0.802 * * *$ & $0.802 * * *$ \\
\hline age: $18-24$ & 0.115 & 0.115 & 0.115 & 0.115 & 0.115 \\
\hline age: $25-34$ & $0.434 * * *$ & $0.434 * * *$ & $0.434 * * *$ & $0.434 * * *$ & $0.434 * * *$ \\
\hline age: $35-44$ & $0.270 * * *$ & $0.270^{* * *}$ & $0.270^{* * *}$ & $0.270^{* * *}$ & $0.270 * * *$ \\
\hline age: $45-54$ & 0.057 & 0.057 & 0.057 & 0.057 & 0.057 \\
\hline age: $55-64$ & 0.003 & 0.003 & 0.003 & 0.003 & 0.003 \\
\hline social grade $\mathrm{C} 1$ & -0.058 & -0.058 & -0.058 & -0.058 & -0.058 \\
\hline social grade $\mathrm{C} 2$ & -0.019 & -0.019 & -0.019 & -0.019 & -0.019 \\
\hline social grade DE & 0.050 & 0.050 & 0.050 & 0.050 & 0.050 \\
\hline low education & $-0.160 * * *$ & $-0.160 * * *$ & $-0.160 * * *$ & $-0.160 * * *$ & $-0.160 * * *$ \\
\hline medium education & -0.012 & -0.012 & -0.012 & -0.012 & -0.012 \\
\hline never married & $0.312 * * *$ & $0.312 * * *$ & $0.312 * * *$ & $0.312 * * *$ & $0.312 * * *$ \\
\hline divorced & $0.347 * * *$ & $0.347 * * *$ & $0.347 * * *$ & $0.347 * * *$ & $0.347 * * *$ \\
\hline widowed & $0.306 * * *$ & $0.306 * * *$ & $0.306 * * *$ & $0.306 * * *$ & $0.306 * * *$ \\
\hline 1 child & 0.038 & 0.038 & 0.038 & 0.038 & 0.038 \\
\hline 2 children & 0.009 & 0.009 & 0.009 & 0.009 & 0.009 \\
\hline$>2$ children & $0.295 * * *$ & $0.295 * * *$ & $0.295 * * *$ & $0.295 * * *$ & $0.295 * * *$ \\
\hline part-time work & $0.199 * * *$ & $0.199 * * *$ & $0.199 * * *$ & $0.199 * * *$ & $0.199 * * *$ \\
\hline student & 0.058 & 0.058 & 0.058 & 0.058 & 0.058 \\
\hline retired & 0.047 & 0.047 & 0.047 & 0.047 & 0.047 \\
\hline unemployed & $0.459 * * *$ & $0.459 * * *$ & $0.459 * * *$ & $0.459 * * *$ & $0.459 * * *$ \\
\hline other work status & $0.457 * * *$ & $0.457 * * *$ & $0.457 * * *$ & $0.457 * * *$ & $0.457 * * *$ \\
\hline constant & $-4.594 * * *$ & $-4.594 * * *$ & $-4.594 * * *$ & $-4.594 * * *$ & $-4.594 * * *$ \\
\hline Observations & 100,357 & 100,357 & 100,357 & 100,357 & 100,357 \\
\hline Region FE & Yes & Yes & Yes & Yes & Yes \\
\hline Date FE & Yes & Yes & Yes & Yes & Yes \\
\hline Standard Error & standard & robust & $\begin{array}{l}\text { Clustered at } \\
\text { region }\end{array}$ & $\begin{array}{l}\text { Clustered at } \\
\text { region-week }\end{array}$ & $\begin{array}{l}\text { Clustered at } \\
\text { region-date }\end{array}$ \\
\hline
\end{tabular}

Note: The outcome variable is the non-compliance binary. The columns differ with respect to the type of the standard error. Region and date fixed effects $(F E)$ are included. Estimates are based on a logistic regression. $* * *, * * *$ denote significance at 1,5 and 10 percent, respectively. 
TABLE A4. LOGISTIC REGRESSIONS WITH DIFFERENT CONTROL VARIABLES

\begin{tabular}{|c|c|c|c|c|c|c|}
\hline Model & (1) & (2) & (3) & (4) & (5) & (6) \\
\hline male & $0.751 * * *$ & $0.748 * * *$ & $0.753 * * *$ & $0.758 * * *$ & $0.802 * * *$ & $0.802 * * *$ \\
\hline age: $18-24$ & $0.424 * * *$ & $0.390 * * *$ & $0.220 * * *$ & $0.157^{*}$ & 0.115 & 0.115 \\
\hline age: $25-34$ & $0.592 * * *$ & $0.567 * * *$ & $0.518 * * *$ & $0.469 * * *$ & $0.434 * * *$ & $0.434 * * *$ \\
\hline age: $35-44$ & $0.412 * * *$ & $0.394 * * *$ & $0.376^{* * *}$ & $0.319 * * *$ & $0.270 * * *$ & $0.270 * * *$ \\
\hline age: $45-54$ & $0.189 * * *$ & $0.189 * * *$ & $0.170 * *$ & $0.118^{*}$ & 0.057 & 0.057 \\
\hline age: $55-64$ & $0.095^{*}$ & $0.096 *$ & $0.092 *$ & 0.076 & 0.003 & 0.003 \\
\hline social grade $\mathrm{C} 1$ & -0.053 & -0.033 & -0.064 & -0.059 & -0.058 & -0.058 \\
\hline social grade $\mathrm{C} 2$ & -0.017 & 0.021 & 0.002 & -0.000 & -0.019 & -0.019 \\
\hline social grade DE & $0.227 * * *$ & $0.272 * * *$ & $0.196 * * *$ & $0.166^{* * *}$ & 0.050 & 0.050 \\
\hline low education & & $-0.153 * * *$ & $-0.149 * * *$ & $-0.136 * * *$ & $-0.16 * * *$ & $-0.160 * * *$ \\
\hline medium education & & 0.008 & 0.006 & -0.003 & -0.012 & -0.012 \\
\hline never married & & & $0.319 * * *$ & $0.340 * * *$ & $0.312 * * *$ & $0.312 * * *$ \\
\hline divorced & & & $0.341 * * *$ & $0.350 * * *$ & $0.347 * * *$ & $0.347 * * *$ \\
\hline widowed & & & $0.301 * * *$ & $0.295 * * *$ & $0.306 * * *$ & $0.306 * * *$ \\
\hline 1 child & & & & 0.051 & 0.038 & 0.038 \\
\hline 2 children & & & & 0.023 & 0.009 & 0.009 \\
\hline$>2$ children & & & & $0.327 * * *$ & $0.295 * * *$ & $0.295 * * *$ \\
\hline part-time work & & & & & $0.199 * * *$ & $0.199 * * *$ \\
\hline student & & & & & 0.058 & 0.058 \\
\hline retired & & & & & 0.047 & 0.047 \\
\hline unemployed & & & & & $0.459 * * *$ & $0.459 * * *$ \\
\hline other work status & & & & & $0.457 * * *$ & $0.457 * * *$ \\
\hline time trend & & & & & & $0.032 * * *$ \\
\hline constant & $-4.565 * * *$ & $-4.541 * * *$ & $-4.588 * * *$ & $-4.552 * * *$ & $-4.594 * * *$ & $-4.626 * * *$ \\
\hline Observations & 104,597 & 104,597 & 103,944 & 100,357 & 100,357 & 100,357 \\
\hline Region FE & Yes & Yes & Yes & Yes & Yes & Yes \\
\hline Date FE & Yes & Yes & Yes & Yes & Yes & Yes \\
\hline
\end{tabular}

Note: The outcome variable is the non-compliance binary. The columns differ with respect to inclusion of independent variables. Estimates are based on a logistic regression robust standard errors clustered at the regional level. Region and date fixed effects $(F E)$ are included. ***,*** denote significance at 1,5 and 10 percent, respectively. 
TABLE A5. REGRESSION RESULTS FOR DIFFERENT MODEL TYPES

\begin{tabular}{|c|c|c|c|c|}
\hline Model & (1) & (2) & (3) & (4) \\
\hline male & $0.802 * * *$ & $0.037 * * *$ & $0.799 * * *$ & $0.037 * * *$ \\
\hline age: $18-24$ & 0.115 & 0.005 & 0.108 & 0.004 \\
\hline age: $25-34$ & $0.434 * * *$ & $0.022 * * *$ & $0.428 * * *$ & $0.022 * * *$ \\
\hline age: $35-44$ & $0.270 * * *$ & $0.013 * * *$ & $0.261 * * *$ & $0.013 * * *$ \\
\hline age: $45-54$ & 0.057 & 0.003 & 0.049 & 0.003 \\
\hline age: $55-64$ & 0.003 & 0.000 & -0.002 & -0.000 \\
\hline social grade $\mathrm{C} 1$ & -0.058 & -0.002 & -0.057 & -0.002 \\
\hline social grade $\mathrm{C} 2$ & -0.019 & -0.000 & -0.022 & -0.000 \\
\hline social grade $\mathrm{DE}$ & 0.050 & 0.003 & 0.049 & 0.003 \\
\hline low education & $-0.160 * * *$ & $-0.007 * * *$ & $-0.164 * * *$ & $-0.007 * * *$ \\
\hline medium education & -0.012 & -0.001 & -0.017 & -0.001 \\
\hline never married & $0.312 * * *$ & $0.016 * * *$ & $0.319 * * *$ & $0.017 * * *$ \\
\hline divorced & $0.347 * * *$ & $0.016 * * *$ & $0.348 * * *$ & $0.016 * * *$ \\
\hline widowed & $0.306^{* * *}$ & $0.013 * * *$ & $0.301 * * *$ & $0.013 * * *$ \\
\hline 1 child & 0.038 & 0.000 & 0.035 & 0.000 \\
\hline 2 children & 0.009 & -0.001 & 0.005 & -0.002 \\
\hline$>2$ children & $0.295 * * *$ & $0.014 * * *$ & $0.291 * * *$ & $0.014 * * *$ \\
\hline part-time work & $0.199 * * *$ & $0.010 * * *$ & $0.195 * * *$ & $0.010 * * *$ \\
\hline student & 0.058 & 0.003 & 0.065 & 0.003 \\
\hline retired & 0.047 & 0.004 & 0.033 & 0.003 \\
\hline unemployed & $0.459 * * *$ & $0.029 * * *$ & $0.453 * * *$ & $0.029 * * *$ \\
\hline other work status & $0.457 * * *$ & $0.024 * * *$ & $0.453 * * *$ & $0.024 * * *$ \\
\hline constant & $-4.594 * * *$ & $-0.012 * *$ & $-4.593 * * *$ & $-0.012^{* *}$ \\
\hline Observations & 100,357 & 100,357 & 100,357 & 100,357 \\
\hline Region FE & Yes & Yes & No & No \\
\hline Date FE & Yes & Yes & Yes & Yes \\
\hline Model & Logistic & $\begin{array}{c}\text { Linear } \\
\text { probability }\end{array}$ & $\begin{array}{l}\text { Multi-level } \\
\text { logistic }\end{array}$ & $\begin{array}{c}\text { Multi-level } \\
\text { generalized linear }\end{array}$ \\
\hline
\end{tabular}

Note: The outcome variable is the non-compliance binary. The columns differ with respect to the regression method applied. All estimations use robust standard errors clustered at the regional level. $* * *, * * *$ denote significance at 1,5 and 10 percent, respectively. 
Figure A5. PREDICTED PROBABILITIES OF NON-COMPLIANCE BY SOLAR RADIATION.

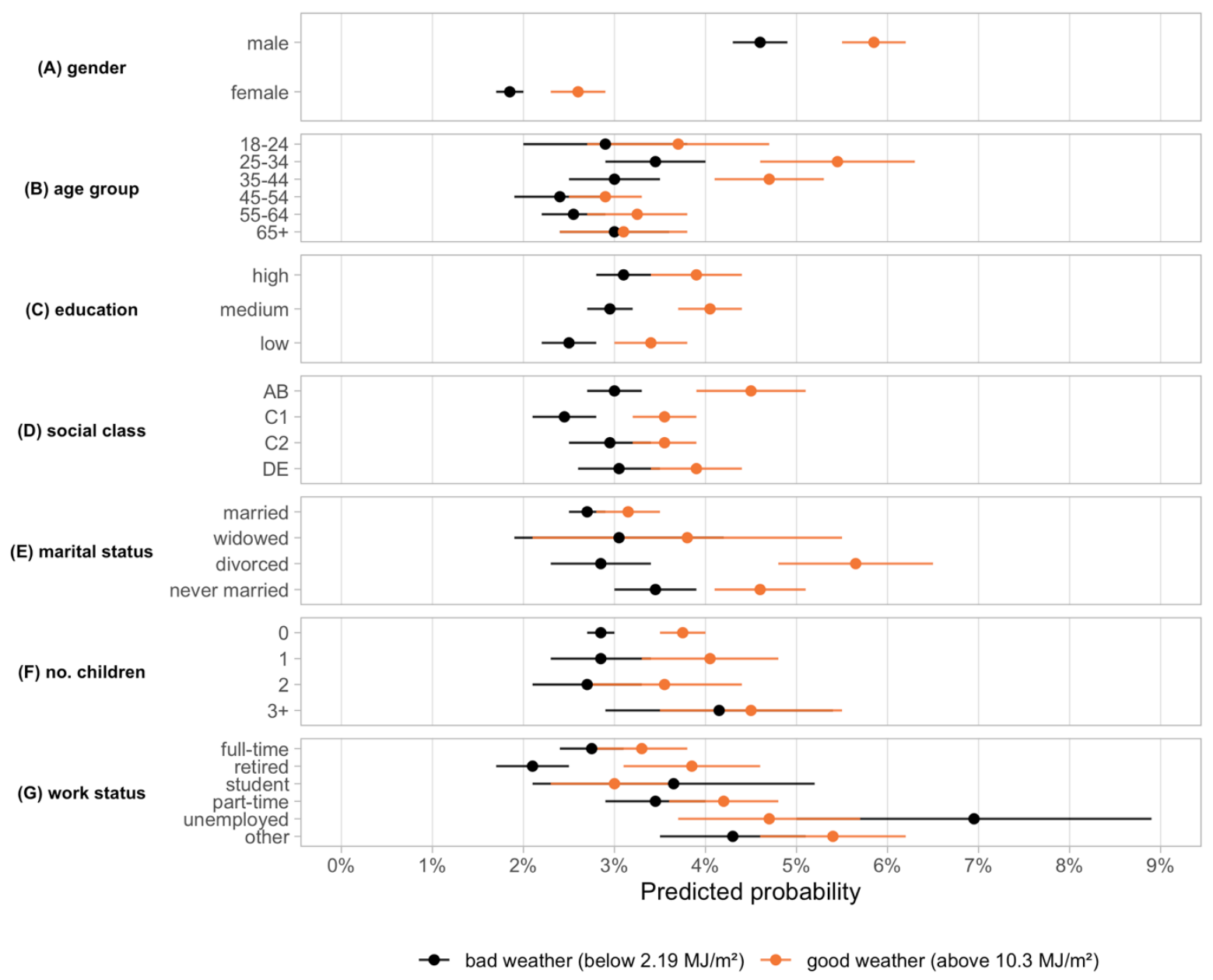

Note: The panels show the predicted probability of non-compliance when a given individual level characteristic being equal to 1 while all other covariates are held constant at their mean values. The black (orange) dots are estimates based on observations under bad (good) weather conditions, which are defined along the top and bottom quartiles $(2.19 \mathrm{MJ} / \mathrm{m} 2$ and $10.3 \mathrm{MJ} / \mathrm{m} 2$, respectively) of net solar radiation. The estimates are based on a logistic regression with date and region fixed effects included and robust standard errors clustered at the region level. The horizontal lines show the $95 \%$ confidence intervals. $N=100,357$. 
Figure A6. Predicted PROBAbILITIES OF NON-COMPLIANCE by PRECIPITATION.

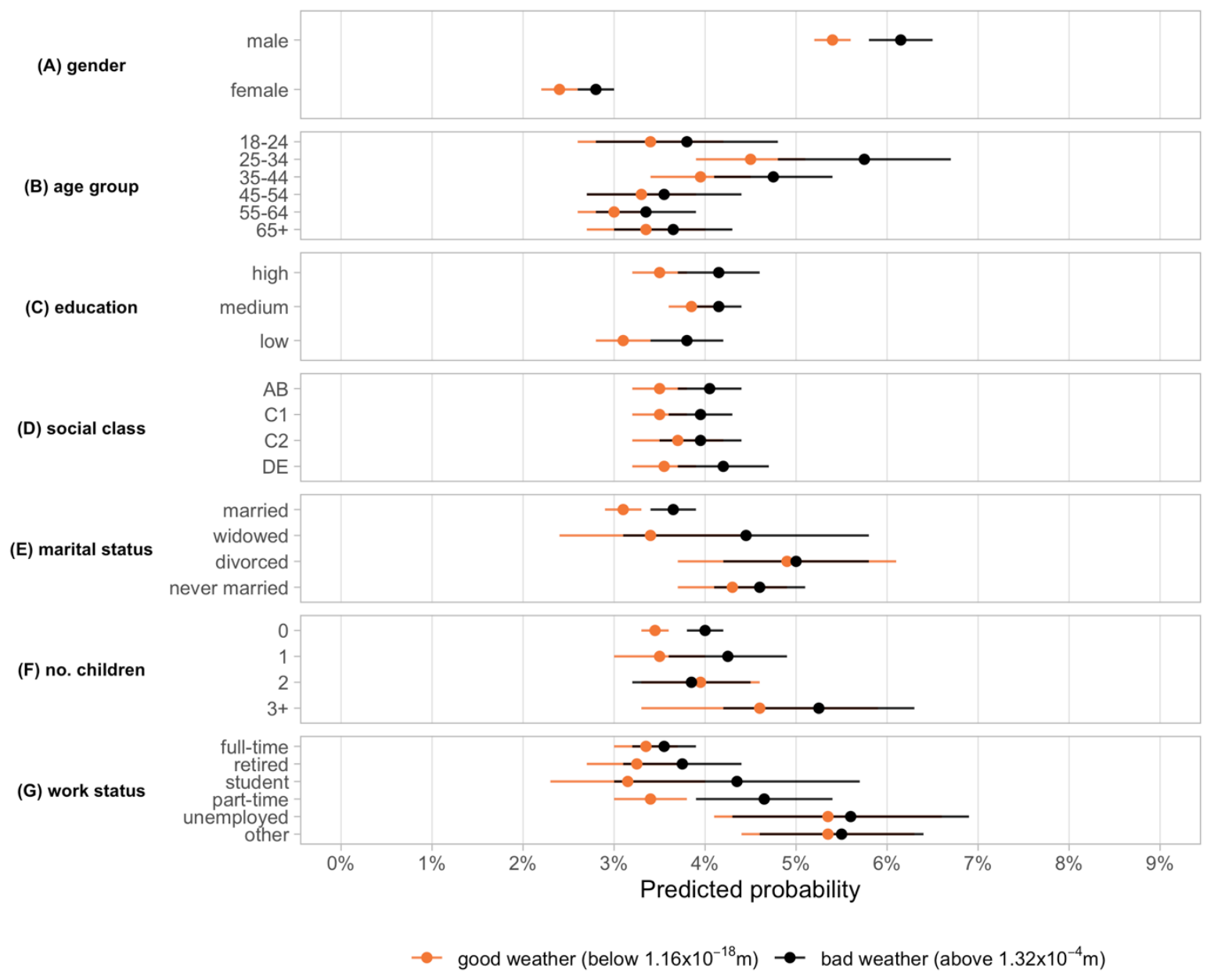

Note: The panels show the predicted probability of non-compliance when a given individual level characteristic being equal to 1 while all other covariates are held constant at their mean values. The black (orange) dots are estimates based on observations under bad (good) weather conditions, which are defined along the top and bottom quartiles (1.16x10-18 $\mathrm{m}$ and 1.32x10-4 m, respectively) of total precipitation. The estimates are based on a logistic regression with date and region fixed effects included and robust standard errors clustered at the region level. The horizontal lines show the 95\% confidence intervals. $N=100,357$. 